five became $\mathrm{HBsAg}$-positive coincident with the fall in antiHBs titres. We have seen another patient with underlying cirrhosis due to chronic active hepatitis in whom a dormant hepatitis $B$ virus infection may also have been reactivated after immunosuppressive treatment. ${ }^{6}$ The acute attack of hepatitis in case 5 may have been due instead, however, to a new infection with a different subtype of hepatitis B virus. Reports of the coexistence of antigen and antibody of different subtypes in the same serum suggest that a second infection can occur in previously exposed individuals. ${ }^{i} 8$

Another difference between cases 1-4 and case 5 lies in the histological findings. Only the patient in case 5 , who remained $\mathrm{HBsAg}$-positive, had orcein-positive hepatocytes, indicating the presence of HBsAg. This supports other observations that positive orcein staining is more typical of those patients who progress to chronic hepatitis B infection. ${ }^{9}$

Patients receiving frequent transfusions for recurrent variceal haemorrhage or given fresh frozen plasma as a cover for liver biopsy are likely to be at greatest risk. Hoofnagle et al ${ }^{10}$ showed that donor blood negative for both $\mathrm{HBs} A g$ and anti-HBs can still be infectious if positive for anti- $\mathrm{HBc}$, and the latter marker may be valuable when the $\operatorname{IgM}$ component is raised. Non-A, non-B hepatitis is also transmitted by transfusion, and we have seen several cases of acute hepatitis due to this infection in patients with chronic liver disease. ${ }^{1}$

We are grateful to the department of chemical pathology and Mrs Hazel Smith for valuable help, and to the Wellcome Trust and the Department of Health and Social Security for generous support.

\section{References}

1 Wyke, R J, et al, Lancet, 1979, 1, 520

2 Anthony, P P, et al, fournal of Clinical Pathology, 1978, 31, 395.

3 Hoofnagle, J H, Gerety, R J, and Barker, L F, Lancet, 1973, 2, 869

${ }^{4}$ Nagington, B, Cossart, Y E, and Cohen, B J, Lancet, 1977, 1, 558.

5 Wands, J R, et al, Gastroenterology, 1975, 68, 105.

6 Villa, E, et al, submitted for publication.

7 Suzaki, T, et al, Immunology, 1976, 117, 2258.

${ }^{8}$ Koziol, D E, et al, Immunology, 1976, 117, 2260.

9 Portmann, B, et al, Gut, 1976, 17, 1.

${ }^{10}$ Hoofnagle, J H, et al, New England fournal of Medicine, 1978, 298, 1379.

(Accepted 31 fuly 1979)

\title{
Comparison of buprenorphine and pethidine given intravenously on demand to relieve postoperative pain
}

\author{
K CHAKRAVARTY, W. TUCKER, M ROSEN, M D VICKERS
}

British Medical fournal, 1979, 2, 895-897

\section{Summary and conclusions}

In a double-blind study of on-demand intravenous analgesia buprenorphine was found to be about 600 times as potent as pethidine. The incidence of side effects was similar with both drugs. The quality of analgesia, subjectively assessed, was good with both drugs using this method of administration.

Provided that its low potential for abuse is substantiated, buprenorphine appears to be a powerful analgesic that may successfully be given intravenously on demand.

\section{Introduction}

Using patient-controlled devices to administer intravenous narcotic analgesics has been described. ${ }^{1-3} \mathrm{~A}$ motorised syringe with a demand hand grip, and containing several important safety features, has been used for pain relief in obstetrics for several years in this hospital. ${ }^{4}$ We report a trial comparing buprenorphine and pethidine in relieving postoperative pain

\footnotetext{
Department of Anaesthetics, Welsh National School of Medicine, Cardiff CF4 4XN

K CHAKRAVARTY, FFARCSI, Commonwealth scholar (present appointment: assistant professor of anaesthesiology, Jipmer, Pondicherry, India)

W TUCKER, FFARACS, research fellow (present appointment: staff anaesthetist, Royal Brisbane Hospital, Queensland, Australia)

M ROSEN, MB, FFARCS, consultant anaesthetist, University Hospital of Wales

M D VICKERS, MB, FFARCS, professor of anaesthetics
}

after upper abdominal surgery, in which we used the final production model of the syringe based on the prototype described. ${ }^{5}$

\section{Subjects and methods}

Apparatus-The demand machine (figure) is a digitally controlled syringe pump' (Cardiff Palliator, from Pye Dynamics Ltd, Bushey, Herts) that delivers preset volumes at a predetermined rate from a disposable Gillette $20 \mathrm{ml}$ syringe. Two digital counters record respectively the total dose and the progress of the current dose. The patient is provided with a press-button hand grip, which must be depressed twice within one second before the machine will respond. This not only prevents the drug from being administered unintentially when the control has been accidentally knocked or dropped but also provides

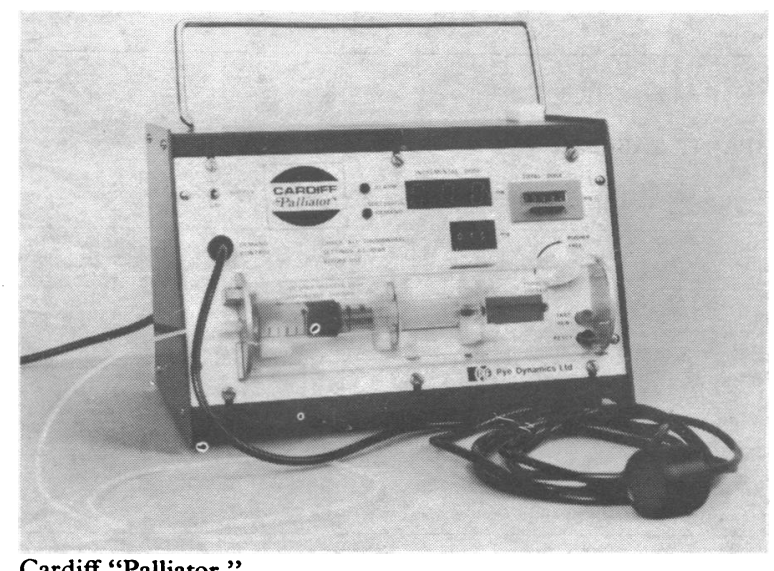

Cardiff "Palliator." 
a crude form of co-ordination test. A further control allows an interval to be prescribed to follow each successful demand, during which no further demands will result in administration of the drug. An output socket allows successful and unsuccessful demands to be recorded and activates an alarm that sounds when the syringe is empty.

Patients-We undertook an open pilot study of 10 patients to establish reasonable doses and an appropriate interval between them. We then undertook a double-blind study of 30 patients, who were randomly allocated to one of two treatments in balanced blocks of 10 . Failure of the recorder at 12 hours in one patient necessitated eliminating that patient from the analysis. Within each block five patients received each drug. Informed, written consent was obtained from each patient before surgery. Patients were not pregnant; were aged between 16 and 70; could co-operate in using the apparatus; were without clinically important hepatic, renal, or cardiorespiratory disease; were not receiving narcotics or monoaminoxidase inhibitors; and were scheduled for upper abdominal surgery.

Drugs-The demand dose of postoperative analgesic was $1 \mathrm{ml}$, infused over two minutes, containing either buprenorphine $90 \mu \mathrm{g}$ or pethidine $30 \mathrm{mg}$, a presumptive potency ratio of 333:1. Drugs were supplied in identical numbered ampoules. As far as possible we avoided using opiate analgesics in premedication and to maintain anaesthesia, but if the anaesthetist considered such an analgesic to be essential on clinical grounds we asked him to use only papaveretum in premedication and fentanyl, in minimal doses, to maintain anaesthesia (see tables Im and IIm for whether opiate analgesics given). Those who received no analgesic supplementation received minimal amounts of halothane as a supplement to a nitrous oxide and oxygen relaxant technique.

\section{PROCEDURES}

The patients were made familiar with the functions of the machine and the control hand grip at the preoperative visit. When the patient arrived in the recovery room the machine was attached to an indwelling intravenous cannula. A syringe containing either $600 \mathrm{mg}$ pethidine $(30 \mathrm{mg} / \mathrm{ml})$ or $1800 \mu \mathrm{g}$ buprenorphine $(90 \mu \mathrm{g} / \mathrm{ml})$ was attached. If the patient complained of pain he was given the hand grip and reminded how to use it. In two cases the first increment was given by the recovery-room nursing staff because the patients had not fully recovered from the effects of the general anaesthesia. The minimum interval between doses was set at five minutes on the basis of the pilot study. Virtually no demands were made within this interval by any patient after the first 15 minutes in the recovery room. Routine postoperative monitoring was supplemented by assessing the effects of each demand on the conscious state and by breath-bybreath monitoring of end-tidal carbon dioxide (Beckman Instruments) from a nasal catheter. This was maintained for six hours. After four to six hours the patients were returned to a general ward still connected to a Cardiff Palliator and event recorder. The patients were observed and managed as usual apart from the administration of analgesics. The empty syringe of drug was replaced with a full one when necessary.

Between 24 and 28 hours each patient was given a series of linear analogues ${ }^{7}$ on which to score his integrated impression of pain and other side effects over the 24 hours after operation. The analogue consisted of a $10-\mathrm{cm}$ horizontal line on plain paper. The patient was instructed (in the case of pain) that the left-hand end of the line represented no pain at all and the right-hand end represented the most

\section{MINIPRINT TABLES}

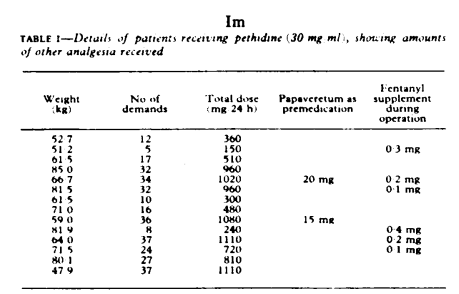

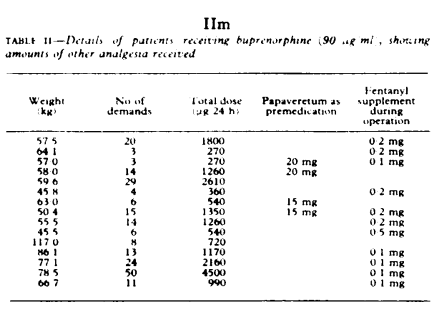

TABLE V1-Mcan analogue scores (and standard ervors) for quality of pain relief and securrty of side effects

\begin{tabular}{|c|c|c|c|c|c|c|}
\hline & $\begin{array}{c}P_{\text {pain }} \\
0=\text { nonc }\end{array}$ & 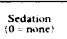 & 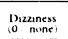 & 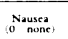 & 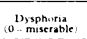 & 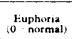 \\
\hline 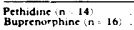 & $\begin{array}{l}279.479 \\
3266401\end{array}$ & $\begin{array}{l}875,791 \\
022,571)\end{array}$ & $\begin{array}{l}1955.501 \\
130153\end{array}$ & 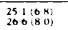 & $\begin{array}{l}543(599) \\
57(1,71)\end{array}$ & $\begin{array}{l}197(6.1) \\
207(1606)\end{array}$ \\
\hline
\end{tabular}

pain he could imagine. The patient was asked to make a vertical mark across the line at the point he thought to be appropriately descriptive for the amount of pain throughout the 24 hours. Similar scores were obtained with analogues for sedation, nausea, dizziness, euphoria, and dysphoria.

\section{Results}

Fourteen patients received pethidine and 15 buprenorphine. Tables Im and IIm give the weights of the patients, the number of successful demands, and the total dose of analgesic taken by each patient in the first 24 hours after operation. Examination of the data suggested some skewness in the total doses: the log doses were more nearly normally distributed than the linear data and not appreciably different from normal. Table III gives the geometric mean total doses per patient and per kilogram, together with the ranges of drug consumption. These extended from $150 \mathrm{mg}$ to $1110 \mathrm{mg}$ for pethidine

TABLE III-Total dosage of analgesia during 24 hours, and relative consumption (pethidine: buprenorphine)

\begin{tabular}{lcccc}
\hline & & & \multicolumn{2}{c}{ Ratio } \\
\cline { 5 - 5 } & $\begin{array}{c}\text { Pethidine } \\
(\mathrm{mg})\end{array}$ & $\begin{array}{c}\text { Buprenorphine } \\
(\mu \mathrm{g})\end{array}$ & Mean & $\begin{array}{c}\text { 95'。 } \\
\text { confidence } \\
\text { limits }\end{array}$ \\
\hline $\begin{array}{l}\text { Mean dose (range) } / \text { patient } \\
\text { (based on log dose) }\end{array}$ & $595(150-1110)$ & $969(270-4500)$ & $614: 1$ & $348-1082: 1$ \\
$\begin{array}{l}\text { Mean dose (range) } / \mathrm{kg} \\
\text { (based on log dose) }\end{array}$ & $9 \cdot 05(2 \cdot 9-23 \cdot 0)$ & $15 \cdot 3(4 \cdot 2-57 \cdot 0)$ & $592: 1$ & $341-1027: 1$ \\
Median dose & 765 & 1170 & $654: 1$ & \\
\hline
\end{tabular}

Suggested working ratio $=600: 1$.

and from $270 \mathrm{\mu g}$ to $4500 \mathrm{ug}$ for buprenorphine. This wide spread was still apparent when allowance was made for the patient's weight (table III). Over the 24 hours the dosage ranged from $2.9 \mathrm{mg} / \mathrm{kg}$ to $23 \mathrm{mg} / \mathrm{kg}$ for pethidine and from $4.2 \mathrm{~kg} / \mathrm{kg}$ to $57 \mu \mathrm{g} / \mathrm{kg}$ for buprenorphine. The median doses were $765 \mathrm{mg}$ and $1170 \mu \mathrm{g}$ respectively.

Using the geometric mean doses and the median doses per patient and per kilogram the potency ratios were variously between 592:1 and $654: 1$. The nearest rounded estimate was $600: 1$ - that is, $100 \mathrm{mg}$ of pethidine being equianalgesic with $0 \cdot 17 \mathrm{mg}$ of buprenorphine. Table IV shows the consumption of analgesic and the standard errors for the intervals 0-3 hours, 3-6 hours, 6-12 hours, and 12-24 hours after operation. In this instance the actual doses were used in the

TABLE IV-Mean $( \pm S E$ of mean) consumptions of buprenorphine $(n=15)$ and pethidine $(n=14)$ from on-demand apparatus

\begin{tabular}{lcccccc}
\hline Time after operation (hours) : & $0-3$ & $3-6$ & $6-12$ & $12-24$ \\
\hline Buprenorphine $(\mu \mathrm{g} / \mathrm{kg} \mathrm{h})$ & $1 \cdot 515 \pm 0 \cdot 265$ & $0 \cdot 890$ & $0 \cdot 249$ & $0 \cdot 714 \pm 0 \cdot 138$ & $0 \cdot 727 \pm 0 \cdot 177$ \\
Pethidine $(\mu \mathrm{g} / \mathrm{kg} / \mathrm{h})$ & $664 \pm 107$ & 432 & 72 & $392 \pm 92$ & $422 \pm 65$ \\
\hline
\end{tabular}

calculation because in some of these intervals some patients did not receive any analgesia. Table $\mathrm{V}$ gives the potency ratios derived from the consumption figures. The fact that they are all less than the

TABLE V-Relative potency (pethidine: buprenorphine) of analgesia over different periods (based on actual doses)

\begin{tabular}{lllcccc}
\hline Time after operation (hours) & $\ldots$ & $0-3$ & $3-6$ & $6-12$ & $12-24$ \\
Relative potency $\quad$. &. & $\ldots$ & $438: 1$ & $485: 1$ & $549: 1$ & $580: 1$ \\
\hline
\end{tabular}

suggested figure of 600 is merely a consequence of the distributions of the data. The ratio increased over time, which, while not conclusive, is compatible with the claim that buprenorphine has a longer duration of action and therefore relatively less of the drug will be needed as time passes.

Table VIm gives the analogue scores for the side effects of sedation, dizziness, nausea, dysphoria, and euphoria. No significant differences were detected between the drugs in any of these parameters, nor in the overall rating of the quality of analgesia. 


\section{Discussion}

Self-adminstration of analgesic was extremely popular with patients; less expectedly, it was also welcomed by the nursing staff. Free access to analgesics did not result in excessive consumption (mean dose of pethidine $595 \mathrm{mg}$ in 24 hours), although some patients certainly took more than would have been conventionally prescribed. The mean analogue score for the overall rating of the intensity of the pain experienced was low (pethidine 27.9 , buprenorphine 32.6 ) and less than that recorded by women after "painless" childbirth with epidural analgesia. ${ }^{8}$ Comparable linear analogues for intramuscular postoperative analgesia regimens using doses of $20 \mathrm{mg}$ of papaveretum yielded considerably higher pain scores. ${ }^{9}$

Individual consumption of analgesic varied widely, in terms of both total dose and dose per kilogram. Some of this biological variation can be attributed to differences in the amount of pain perceived, which correlates with personality, ${ }^{10}$ while some is probably attributable to different sensitivity to the drugs. No standard intramuscular regimen could be expected to cope with these differences. Self-administration may be expected to minimise those side effects that can be attributed to overdose with either drug.

The failure to detect any significant difference in the rating of side effects may be due to the numbers studied. Such differences as were detected were in favour of buprenorphine, which even scored higher for euphoria. If this drug's low dependence potential is confirmed this will encourage its increasing use.
The relative potency suggested on the basis of this trial is at variance with the amounts of the drugs supplied per ampoule, and giving an ampoule of buprenorphine $(0.3 \mathrm{mg})$ on the assumption that it is equianalgesic with $100 \mathrm{mg}$ of pethidine would result in a relatively higher dose of buprenorphine.

The actual delivery of intravenous drugs by self-demand requires some care. The drugs should not be injected into an infusion line unless a unidirectional valve prevents retrograde injection up the tubing. Without this, several doses may accumulate in the tubing if the infusion is blocked at the needle. A suitable disposable valve is obtainable from Vygon Ltd.

\section{References}

${ }^{1}$ Sechzer, P H, Anesthesia and Analgesia . . . Current Researches, 1971, 50, 1.

2 Forrest, W H, Smethurst, P W R, and Kienitz, M E, Anesthesiology, 1970, 33, 363.

${ }^{3}$ Keeri-Szanto, M, Canadian Anaesthetists' Society fournal, 1971, 18, 581.

4 Evans, J M, et al, Anaesthesia, 1976, 31, 847.

5 Evans, J M, et al, Lancet, 1976, 1, 17.

6 McCarthy, J, et al, IERE Conference Proceedings, Applications of Electronics in Medicine. London, Institute of Electronic and Radio Engineers, 1976. Revill, S I, et al, Anaesthesia, 1976, 31, 1191.

${ }^{8}$ Robinson, J O, et al, British fournal of Obstetrics and Gynaecology. In press.

${ }^{9}$ Henderson, J J, and Parbrook, G D, British fournal of Anaesthesia, 1976, 48, 587.

${ }^{10}$ Parbrook, G D, Steel, D F, and Dalrymple, D G, British fournal of Anaesthesia, 1973, 45, 21.

(Accepted 7 August 1979)
ONE HUNDRED YEARS AGO It is not a little curious how tardily our cathedral towns resign their ancient and prescriptive right to be unhealthy and to maintain a high death-rate. This unwillingness to march with the times is doubtless a relic of the Middle Ages, when sanctity and filth were indissolubly connected. However this may be, it is certain that our cities are too often brought into unpleasant prominence through the prevalence within them of preventable diseases. Lincoln, Peterborough, and Carlisle will at once rise to the mind as examples of unhealthy cities; and recently public attention has been drawn to the waste of infant life at Exeter, Norwich, and Worcester. The guardians of the former place have been taking the question seriously to heart; and it is to be hoped that the authorities of Worcester will do the same, now that they have before them the clear and painstaking special report which Dr Strange, the medical officer of health, has lately submitted to them. Dr Strange has evidently been at great pains to discover a reason for the distressing infantile mortality in his city, and it is to be regretted that he has not succeeded in obtaining more definite results. He thinks that the great bulk of the deaths can only be explained by the ignorance, neglect, or poverty of the parents; but he does not give us such exact details as could be desired for the proving of this theory. It is obvious that to ascribe the major part of the deaths to influences of this sort is to beg the question, and we would recommend Dr Strange to make this year even more exact inquiry as to the sanitary surroundings of the children than he did in 1878. Many of the deaths appear to have occurred in unwholesome courts, to which the Artisans' Dwelling Act is proposed to be applied; and we should be inclined to assign much more of the mortality to the influence of foul air than $\mathrm{Dr}$ Strange has done. It is right, however, to state that no fewer than one hundred and eighty-three out of the total number of three hundred and fifty-seven deaths of children under five years of age occurred from diseases of the digestive organs, such as inanition, marasmus and atrophy, convulsions, mesenteric disease, diarrhoea, etc; and that of these, one hundred and two, or more than a half, died before they reached six months of age. Another point in Dr Strange's favour is that as large a proportion as two-thirds of the total infantile deaths occurred in the families of artisans, in classifying whom none have been included whose employment should not have placed them far above poverty. We are disposed to think, however, that there is some other condition which tends to make infant life precarious in Worcester, and which further and more searching inquiry will bring out. We would suggest, therefore, to Dr Strange to continue for some time to come the inquiry which he has so well begun. (British Medical fournal, 1879.)

\section{Vancouver style}

All manuscripts submitted to the $B M Y$ from now on should conform to the uniform requirements for manuscripts submitted to biomedical journals (known as the Vancouver style).

The $B M \mathcal{A}$, together with many other international biomedical journals, has agreed to accept articles prepared in accordance with the Vancouver style and will be introducing the system from January 1980 . The style (described in full in $B M \mathcal{F}, 24$ February, p 532) is intended to standardise requirements for authors and covers text format, presentation of methods and results, use of SI units, and the form of tables and illustrations. All the participating journals have also agreed to introduce a standard form of references.

In future references to papers submitted to the $B M \mathcal{F}$ should include: the names of all authors if there are fewer than seven or, if there are more, the first three followed by et al; the title of journal articles or book chapters; the titles of journals abbreviated according to the style of Index Medicus; and the first and final page numbers of the article or chapter.

Examples of common forms of references are:

${ }^{1}$ International Steering Committee of Medical Editors. Uniform requirements for manuscripts submitted to biomedical journals. $\mathrm{Br}$ Med $\mathcal{F} 1979 ; 1$ : 532-5.

2 Soter NA, Wasserman SI, Austen KF. Cold urticaria: release into the circulation of histamine and eosinophil chemotactic factor of anaphylaxis during cold challenge. $N$ Engl f Med 1976; 294: 687-90.

3 Weinstein L, Swartz, MN. Pathogenic properties of invading micro-organisms. In: Sodeman WA Jr, Sodeman, WA, eds. Pathologic physiology: mechanisms of disease. Philadelphia, W B Saunders, 1974: 457-72.

Up to the beginning of October some 100 journals had agreed to accept articles in the Vancouver style, and a full list will be printed early in 1980 . 